\title{
The influence of the cycloid disc bearing type on the cycloidal speed reducer efficiency
}

\author{
Milan Vasic ${ }^{1}$, Mirko Blagojevic ${ }^{1}$, Miloš Matejic ${ }^{1},{ }^{*}$, and Ileana Ioana Cofaru ${ }^{2}$ \\ ${ }^{1}$ University of Kragujevac, Faculty of Engineering, 34000 Kragujevac, Sestre Janjic 6, Serbia \\ 2"Lucian Blaga" University of Sibiu, Computer Science \& Electrical Engineering Department, \\ 550075 Sibiu, Str. Emil Cioran, Nr. 4, Romania
}

\begin{abstract}
The robotics industry has experienced a rapid expansion in the last decade. As a result, the market of speed reducers with high gear ratios, high precision and a compact design is growing rapidly. In addition to these characteristics, it is very important for gear trains to have high efficiency. Because of their compact design, cycloidal speed reducers are not exposed to axial forces, which is their important characteristic. This means that radial bearings can be used in their supports. The bearing type has significant effects not only on the design and dimensions of the cycloid speed reducer but also on its efficiency. In this paper, an analysis of power losses for different types of rolling bearings of a cycloid disc has been performed. At the end of the paper, concrete conclusions are presented as well as directions for future research.
\end{abstract}

\section{Introduction}

The industrial revolution that we are experiencing nowadays brings advancement and automation of modern equipment and a widespread use of artificial intelligence. People still play a leading role in the production process, but industrial robots are being increasingly used in the process of packaging, welding, testing and assembly in the automatic production chain. Although industrial robots consist of a large number of mechanical and electrical components, high precision speed reducers are one of the most important components. They are mainly planetary, wave and cycloidal speed reducers.

Cycloidal speed reducers meet high requirements such as a compact design, long and reliable service life, high efficiency, very low idle speed when starting off and stopping, low noise level, low vibration, etc. Generally, efficiency is the most important performance characteristic both for reducing energy consumption and increasing productivity of industrial robots.

In the literature, there are a lot of papers dealing with efficiency of cycloidal speed reducers. Malhotra [1] was the first to define analytical expressions for calculation of power losses at different locations of cycloidal speed reducers. Sensinger [2] used optimisation in order to increase the efficiency of the cycloidal speed reducer. Mackic [3] studied the influence of geometric parameters on the cycloid speed reducer efficiency. Mihailidis [4]

${ }^{*}$ Corresponding author: mmatejic@kg.ac.rs 
presented a new approach to determining efficiency by calculating the friction coefficient at each contact point. Olejarczyk analysed the influence of mineral and synthetic oil on efficiency [5]. Pham, Bednarczyk et al. [6-8] analysed the effects of machining tolerances on efficiency. In the last few decades, there have been comprehensive studies in the field of defining new concepts of cycloid speed reducers [9,10], modifying the cycloid disc tooth profile [11], dynamic analysis [12,13] and stress-strain analysis of vital elements [10, 14].

Based on the review of the literature, it can be concluded that researchers have addressed various issues in order to improve the efficiency of cycloidal speed reducers. In this regard, the aim of this paper is to compare power losses for different types of cycloid disc bearings.

Although, due to their compact design, needle bearings are most often used for cycloid discs, this paper gives a comparative analysis of the use of needle, cylindrical and ball bearings.

\section{Power losses in cycloidal speed reducers}

In general, power losses in cycloidal speed reducers can be divided into load-independent and load-dependent losses which occur between the elements in contact $[4,5,15]$. Apart from the operating conditions and the internal design of the housing, the load-independent losses are mainly related to the viscosity and density of the lubricant, the immersion depth of the parts in the oil bath [16], and the shaft seals (Fig. 1 - h, i). Load-dependent losses can be divided into power losses in $[1,4,5,15]$ :

- the cycloid disc bearing (Fig. $1-$ a);

- the contact between the output rollers and holes in the cycloid disc (Fig. 1-b);

- the contact of the output rollers and their pins (Fig. $1-\mathrm{c}$ );

- the contact of the central rollers and cycloid disc teeth (Fig. 1-d);

- the contact between the central rollers and their pins (Fig. 1 - e);

- the input shaft bearings (Fig. $1-\mathrm{g}$ );

- the output shaft bearings (Fig. $1-\mathrm{k}, \mathrm{j}$ ).

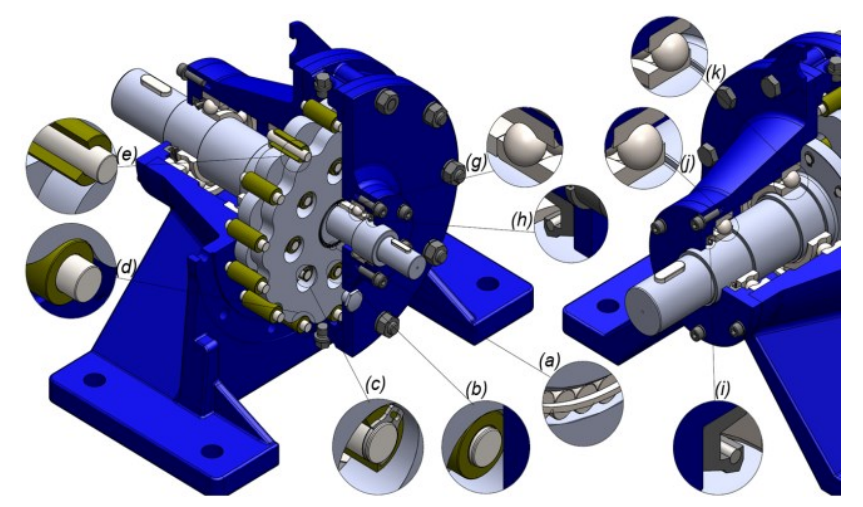

Fig. 1. Power losses in contacts between the cycloid speed reducer elements.

Total theoretical efficiency of cycloid reducer $\eta$ can be calculated bu usage of Malohotra's [1] equation which is based on difference in input torque of cycloid reducer $T_{\text {in }}(\mathrm{Nmm})$ and total work of friction forces $W_{\text {loss }}(\mathrm{Nmm})$ which is caused by losses in previously defined zones:

$$
\eta=\frac{T_{i n} \cdot 2 \pi-W_{\text {loss }}}{T_{i n} \cdot 2 \pi}
$$


This paper studies power losses in the cycloid disc bearing because they have a great effect on the cycloidal speed reducer efficiency. Reducing bearing friction is an absolute imperative both for manufacturers and researchers working in this field. Friction occurs regardless of the type and size of the bearing, i.e. regardless of the characteristics and amount of the lubricant. It is expressed by the frictional torque. The lost energy is mostly converted into heat [17-19].

\section{Mathematical model for calculation of the cycloid disc bearing efficiency}

Many authors have been engaged in research and development of efficient mathematical models for determination of the frictional torque of rolling bearings, and one of the most acceptable models was proposed by Palmgren [20]. He developed simple theoretical and empirical expressions for which the necessary parameters can be found in the manufacturers' catalogues and which have the widest application in engineering practice. The expressions are defined based on laboratory tests carried out under different loads, rotational speeds and using different lubricants.

According to Palmgren, the total frictional torque $T_{B \text { loss }}(\mathrm{Nmm})$ for ball bearings consists of a load-dependent component $T_{1}(\mathrm{Nmm})$ and a component dependent on the lubricant viscosity $T_{v}(\mathrm{Nmm})$, i.e.:

$$
T_{\text {B loss }}=T_{1}+T_{v}
$$

For cylindrical roller bearings, in addition to these two components, another frictional torque component is added due to the friction between the rolling elements and the flanges on the rings, i.e. $[21,22]$ :

$$
T_{B \text { loss }}=T_{1}+T_{v}+T_{f}
$$

According to Schaeffer's [22] recommendation, the expression (1) can be applied to needle bearings if factors for this type of bearing are used.

The load-dependent frictional torque component is determined by the following expression:

$$
T_{1}=f_{1} \cdot F_{\beta} \cdot D_{S R}
$$

where : $f_{1}$ - the factor dependent on the bearing type and relative load, $F_{\beta}$ - bearing load which in the case of a cycloidal speed reducer equals the maximum eccentric cam velocity for $\pi$ rotational speed of the input shaft, i.e. $F_{\beta}=F_{\text {e max }}(N), D_{S R}=\left(d_{c z}+D_{c z}\right) / 2-$ the mean diameter of the cycloid disc bearing $(\mathrm{mm}), d_{c z}$ - the inner diameter of the bearing $(\mathrm{mm}), D_{c z}$ - the outer diameter of the bearing $(\mathrm{mm})$.

Eccentricity force $F_{e}(N)$ is determined as resultant of horizontal $F_{e H}(N)$ and vertical $F_{e V}(N)$ force component $[23,24]$ :

$$
F_{e}=\sqrt{{F_{e H}}^{2}+F_{e V}^{2}}
$$

Horizontal force component is determined according to equation:

$$
F_{e H}=\sum_{i} F_{N i} \cdot \sin x_{i}+\sum_{j} F_{K j}
$$


where are: $F_{N i}$ - normal force on $i$-th central roller $(N), x_{i}$ - angle between meshing force on $i$-th ring gear roller and vertical direction $\left({ }^{\circ}\right), F_{K j}$ - output force on $j$-th output roller $(N)$.

Vertical force component is determined according to equation:

$$
F_{e V}=\frac{T_{i n}}{e}
$$

where is: $e$ - eccentricity size $(\mathrm{mm})$.

Since the entire amount of lubricant cannot pass between the contact surfaces of the rolling body and the raceway, only a small amount of the lubricant form a hydrodynamic film. The excess lubricant which cannot pass between the rolling surfaces becomes resistance to movement.

Therefore, the component of the frictional torque moment that results from the resistance of the lubricant to the movement of the rolling body is determined according to the expression:

$$
\begin{array}{cc}
T_{v}=10^{-7} \cdot f_{o} \cdot\left(v \cdot n_{\text {in }}\right)^{2 / 3} \cdot D_{S R}{ }^{3} & v \cdot n_{\text {in }} \geq 2000 \\
T_{v}=160 \cdot 10^{-7} \cdot f_{o} \cdot D_{S R}{ }^{3} & v \cdot n_{\text {in }}<2000
\end{array}
$$

where: $f_{o}$ - the factor dependent on the bearing type and lubrication method, $v$ - kinematic viscosity of the lubricant at operating temperature, and in case of grease, the predominant factor is the viscosity of the base oil at operating temperature $\left(\mathrm{mm}^{2} \mathrm{~s}^{-1}\right), n_{\text {in }}$ - input rotational speed $\left(\mathrm{min}^{-1}\right)$.

The component of the frictional torque resulting from the resistance between the rollers and the flanges of the ring is determined based on the following expression:

$$
T_{f}=f_{f} \cdot F_{a} \cdot D_{S R}
$$

where: $f_{f}$ - the factor dependent on the bearing type and lubrication method, $F_{a}-$ axial bearing load $(N)$.

The overall power loss in the roller bearing $P_{B \text { loss }}(W)$ is determined based on the expression [22]:

$$
P_{B \text { loss }}=T_{B \text { loss }} \cdot \frac{n_{\text {in }}}{9550}
$$

\section{Comparative analysis of power losses in the cycloid disc bearing}

The following rolling bearings were used in the comparative analysis of power losses in the cycloid disc bearing:

- a needle roller and cage assembly - K 35x40x13;

- a cylindrical roller bearing - NU 1007;

- a deep groove ball bearing -6007 .

Therefore, for the purposes of this research, a single-stage cycloidal speed reducer with the characteristics shown in Table 1 was used. Table 2 shows the dimensions of different types of bearings and the values of the pitch circle radius $R_{\text {Oiz }}$ of the output rollers, which depends on the bearing type. Lithium grease LGMT 2 was used as a lubricant. Its kinematic viscosity at a temperature of $40{ }^{\circ} \mathrm{C}$ is $v_{40}=110 \mathrm{~mm}^{2} / \mathrm{s}$ [25].

Fig. 2a shows the geometric quantities of the vital elements of the cycloidal speed reducer, while Fig. 2b shows the basic geometric differences between cycloid discs with different 
bearing types. It can be noticed that needle cage bearings requires a significantly smaller central hole in the cycloid disc. The size of the central hole in the cycloid disc has a direct effect on the static and dynamic stability of the cycloid disc.

Table 1. Characteristics of the single stage cycloidal speed reducer used for experimental testing.

\begin{tabular}{|c|c|c|c|}
\hline Characteristics & Value & Characteristics & Value \\
\hline Input power, $P_{E M}(W)$ & 4 & $\begin{array}{l}\text { Diameter of the central roller base, } \\
d_{0}(\mathrm{~mm})\end{array}$ & 8 \\
\hline Reducer ratio, $u_{C R}$ & 13 & Number of output rollers, $u$ & 8 \\
\hline $\begin{array}{l}\text { Pitch circle radius of the ring gear, } \\
r(\mathrm{~mm})\end{array}$ & 86 & Output roller diameter, $D_{V K}(\mathrm{~mm})$ & 14 \\
\hline Eccentric cam, $e(\mathrm{~mm})$ & 4 & $\begin{array}{l}\text { Diameter of the output roller base, } \\
d_{V K}(\mathrm{~mm})\end{array}$ & 7 \\
\hline Central roller diameter, $D_{0}(\mathrm{~mm})$ & 14 & \begin{tabular}{|l} 
Diameter of the cycloid disc hole, \\
$D_{O C Z}(\mathrm{~mm})$
\end{tabular} & 29 \\
\hline
\end{tabular}

Table 2. Dimensions of different bearing types.

\begin{tabular}{|l|c|c|c|}
\hline \multicolumn{1}{|c|}{ Quantities } & K 35x40x13 & NU 1007 & $\mathbf{6 0 0 7}$ \\
\hline Pitch circle radius of the output rollers, $R_{\text {Oiz }}(\mathrm{mm})$ & 47.5 & 53 & 53 \\
\hline Inner diameter of the bearing, $d_{C Z}(\mathrm{~mm})$ & 35 & 35 & 35 \\
\hline Outer diameter of the bearing, $D_{C Z}(\mathrm{~mm})$ & 40 & 62 & 62 \\
\hline Bearing width, $B(\mathrm{~mm})$ & 13 & 14 & 14 \\
\hline Dynamic load capacity, $C(\mathrm{kN})$ & 15,4 & 41,5 & 16,8 \\
\hline
\end{tabular}

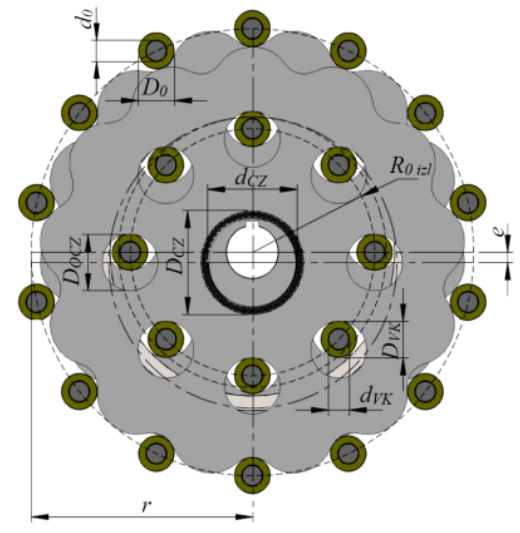

a)

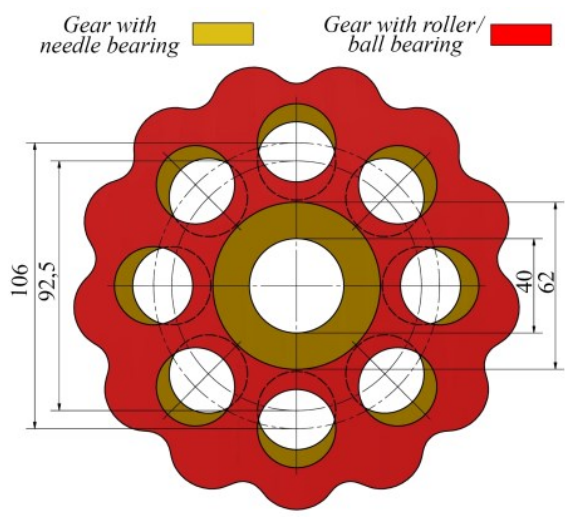

b)

Fig. 2. Geometrical values of the vital cycloid speed reducer elements $(a)$; Dimensions of cycloid discs with different bearing types $(b)$.

From a financial point of view, needle cage bearings are the cheapest roller bearings in relation to the dynamic load capacity, while cylindrical roller bearings are the most expensive. However, since needle cage bearings are placed between the eccentric cam and the cycloid disc, the value of the frictional torque largely depends on the clearances between the contact surfaces, which is not the case with the ball and cylindrical bearings whose rolling bodies are placed between the inner and outer ring.

Fig. 3 shows distribution of the eccentric cam force $F_{e}(N)$ on the cycloid disc determined according to Lehmann [23]. This distribution also applies to the second cycloid disc which is turned at the angle of $180^{\circ}$ to the first one. 


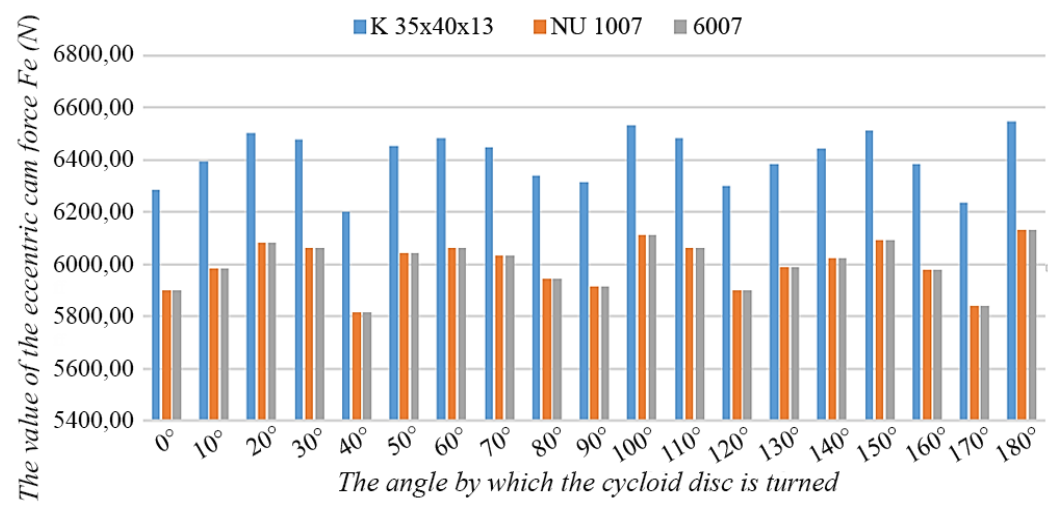

Fig. 3. Distribution of the eccentric cam force $F_{e}(N)$ for the analysed cycloid speed reducer.

The presented force distribution should be considered approximate because Lehman's model [23] does not take into account modifications of the cycloid disc tooth profile and elastic deformations of the elements involved in the load transfer process [26].

In the theoretical case, when there are no clearances in the cycloidal speed reducer, both cycloid discs are in contact with half of the central and output rollers that participate in the load transfer process. However, in reality this is not the case because clearances exist due to manufacturing faults, in order to enable easier assembly and disassembly, better lubrication, etc. The size of the clearances directly affects the number of the rollers in the contact with the cycloid disc - the larger the clearances, the smaller the number of the loaded rollers. This causes changes in the values of the calculated forces.

Fig. 4 shows the dependence of the frictional torque $T_{B \text { loss }}(\mathrm{Nmm})$ on the rotational speed of the input shaft $n_{\text {in }}\left(\mathrm{min}^{-1}\right)$ for the cycloidal speed reducer with the characteristics given in Tables 1 and 2. The rotational speed of the input shaft varies in the range from 500 to 5000 $\mathrm{min}^{-1}$. As the rotational speed increases, the frictional torque decreases. It reaches the highest values when the train gear starts off.

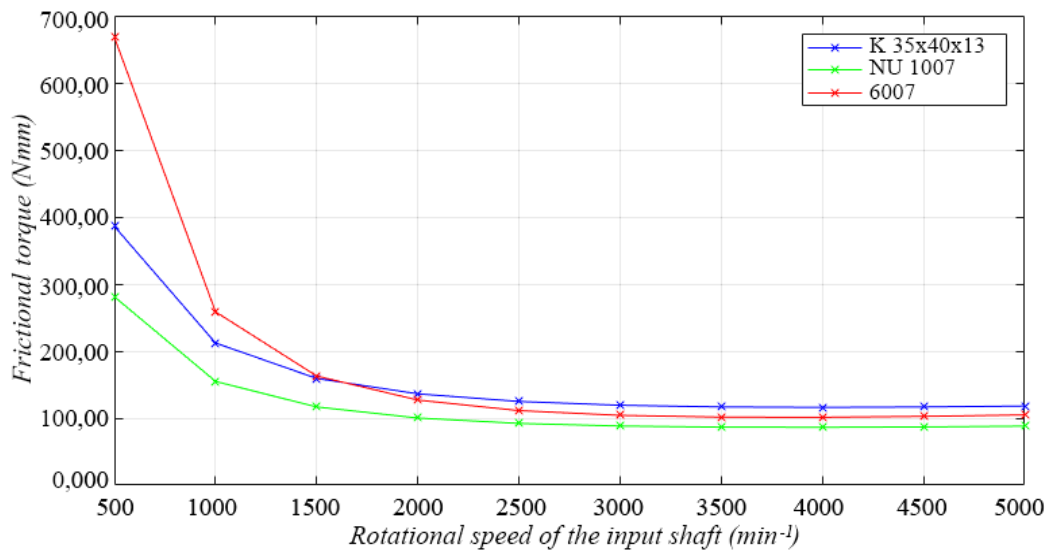

Fig. 4. Dependence of the frictional torque on the rotational speed of the input shaft.

The dependence of the power loss $P_{B \text { loss }}(W)$ on the rotational speed of the input shaft $n_{\text {in }}\left(\mathrm{min}^{-1}\right)$ is shown in Fig. 5, while the percentage differences are given in Tables 3 and 4. As in the previous simulation, the rotational speed of the input shaft varies in the range from 500 to $5000 \mathrm{~min}^{-1}$. With an increase in the rotational speed, the power losses also increase, and the smallest losses occur when the gear train starts off (except for the ball bearing 6007). The values of power losses are similar for all the three types of bearings, but 
the smallest losses occur with the cylindrical roller bearing NU 1007. The power losses are less with the needle cage bearing K 35x40x13 than with the ball bearing 6007 but only at low rotational speeds. As the rotational speed increases, it becomes quite the opposite.

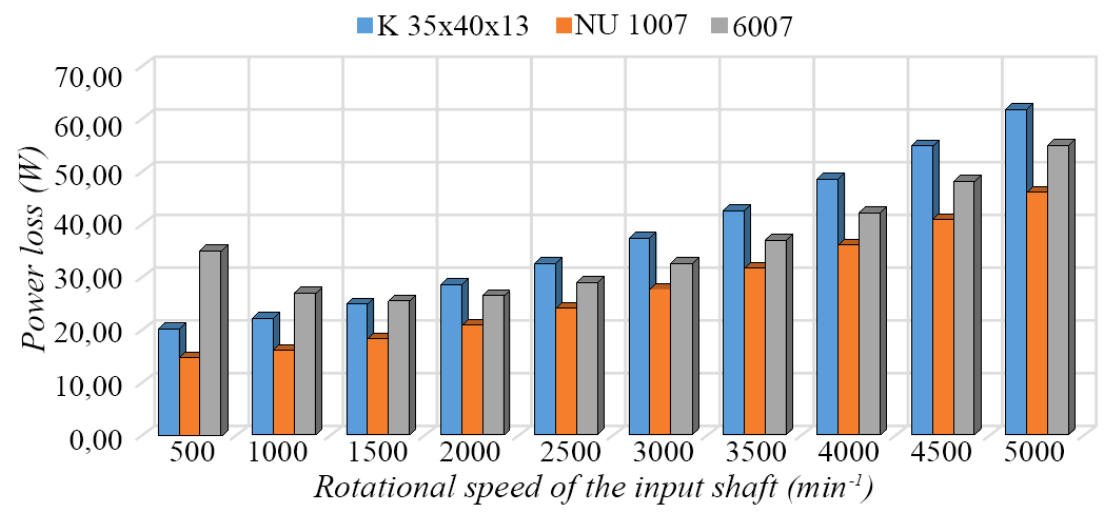

Fig. 5. Dependence of the power loss on the rotational speed of the input shaft.

Table 3. Percentage difference in the power loss between the bearings K 35x40x13 and NU 1007.

\begin{tabular}{|c|c|c|c|c|c|c|c|c|c|c|}
\hline $\boldsymbol{P}_{\text {B loss }}(\boldsymbol{W})$ & $\mathbf{5 0 0}$ & $\mathbf{1 0 0 0}$ & $\mathbf{1 5 0 0}$ & $\mathbf{2 0 0 0}$ & $\mathbf{2 5 0 0}$ & $\mathbf{3 0 0 0}$ & $\mathbf{3 5 0 0}$ & $\mathbf{4 0 0 0}$ & $\mathbf{4 5 0 0}$ & $\mathbf{5 0 0 0}$ \\
\hline K 35x40x13 & 20.201 & 22.194 & 25.002 & 28.518 & 32.678 & 37.434 & 42.750 & 48.599 & 54.957 & 61.804 \\
\hline NU 1007 & 14.702 & 16.205 & 18.324 & 20.977 & 24.115 & 27.702 & 31.713 & 36.125 & 40.922 & 46.088 \\
\hline Difference & $27.22 \%$ & $26.98 \%$ & $26.71 \%$ & $26.44 \%$ & $26.20 \%$ & $25.99 \%$ & $25.82 \%$ & $25.67 \%$ & $25.54 \%$ & $25.43 \%$ \\
\hline
\end{tabular}

Table 4. Percentage difference in the power losses between the bearings K 35x40x13 and 6007 .

\begin{tabular}{|c|c|c|c|c|c|c|c|c|c|c|}
\hline $\boldsymbol{P}_{\text {B loss }}(\boldsymbol{W})$ & $\mathbf{5 0 0}$ & $\mathbf{1 0 0 0}$ & $\mathbf{1 5 0 0}$ & $\mathbf{2 0 0 0}$ & $\mathbf{2 5 0 0}$ & $\mathbf{3 0 0 0}$ & $\mathbf{3 5 0 0}$ & $\mathbf{4 0 0 0}$ & $\mathbf{4 5 0 0}$ & $\mathbf{5 0 0 0}$ \\
\hline K 35x40x13 & 20.201 & 22.194 & 25.002 & 28.518 & 32.678 & 37.434 & 42.750 & 48.599 & 54.957 & 61.804 \\
\hline $\mathbf{6 0 0 7}$ & 34.955 & 27.062 & 25.563 & 26.580 & 29.100 & 32.708 & 37.193 & 42.430 & 48.338 & 54.859 \\
\hline Difference & $-42.21 \%$ & $-17.99 \%$ & $-2.19 \%$ & $6.80 \%$ & $10.95 \%$ & $12.62 \%$ & $13.00 \%$ & $12.69 \%$ & $12.04 \%$ & $11.24 \%$ \\
\hline
\end{tabular}

\section{Conclusion}

This paper presents a comparative analysis of the power loss values in different rolling bearing types of a cycloid disc. The testing was performed on the actual cycloidal speed reducer with the power of $4 \mathrm{~kW}$ and the gear ratio of 13 . The rotational speed varied in the range from 500 to $5000 \mathrm{~min}^{-1}$.

The analysis of the results shows that the power losses are significantly lower with the cylindrical roller bearing NU 1007 than with the needle bearing K $35 \times 40 \times 13$. The losses are $25-27 \%$ lower at all rotational speeds. With the ball bearing 6007 , power losses occur at lower rotational speeds. With higher rotational speeds of the input shaft (over $1500 \mathrm{~min}^{-1}$ ), the losses decrease. Therefore, the power losses are 6-11\% lower compared to the needle cage bearing $\mathrm{K} 35 \times 40 \times 13$. From the aspect of dynamic loading capacity, the cylindrical roller bearing NU 1007 has an extremely high value of $41.5 \mathrm{kN}$, while the ball bearing 6007 $(16.8 \mathrm{kN})$ and the needle cage bearing $\mathrm{K} 35 \times 40 \times 13(15.4 \mathrm{kN})$ have much smaller values. Therefore, compared to other bearing types, the bearing NU 1007 has a significantly longer service life i.e. it achieves higher rotational speeds or a larger number of operating hours before material fatigue occurs. If we consider dimensions, we can conclude that the needle cage bearing $\mathrm{K} 35 \times 40 \times 13$ requires a significantly smaller central hole in the cycloid disc 
compared to the ball bearing 6007 and the cylindrical roller bearing NU 1007 which require a $35.5 \%$ larger diameter. The size of the central hole in the cycloid disc has a direct effect on the static and dynamic stability of the cycloid disc, which is the main reason the needle bearings are so widely used. In our future research we are planning to investigate static and dynamic stability of cycloid discs with different types of bearings as well as to perform a comparative analysis.

Acknowledgment: This paper is a result of TR33015 project of the Ministry of Education, Science and Technological Development, in Serbia. The projects is titled "Research and development of a Serbian zero-net energy house". We would like to thank the Ministry of Education, Science and Technological Development on its financial support during this research.

\section{References}

1. S. K. Malhotra, M. A. Parameswaran, Mech. Mach. Theory, 18, 491 (1983)

2. J. Sensinger. Journal of Mech. Des., 132, 2 (2010)

3. T. Mackic, M. Blagojevic, Z. Babic and N. Kostic, J. Bal. Trib. Assoc., 19, 167 (2013)

4. A. Mihailidis, E. Athanasopoulos, K. Agouridas, Proc. of the Inst. of Mech. Eng. - Part C, 230, $1303(2016)$

5. K. Olejarczyku, M. Wiklo, K. Krol, K. Kołodziejczyk, Model. inży., 33, 74 (2017)

6. A. D. Pham, H. J. Ahnb, J. of Fric. and Wear, 38, 490 (2017)

7. S. Bednarczyk., Proc. of the 14th Inter. Sci. Conf.: Com. Aid. Eng., 55 (2019)

8. S. Bednarczyk, L. Jankowski, J. Krawczyk, Trib., 3, 19 (2019)

9. P. Davoli, C. Gorla, F. Rosa, C. Longoni, F. Chiozzi, A. Samarani, Inter. Des. Eng. Tech. Conf. and Comp. and Inf. in Eng. Conf., 7, 1043 (2007)

10. M. Blagojevic, N. Marjanovic, Z. Djordjevic, B. Stojanovic, A. Disic, J. of Mech. Des., 133, 8, 085001-1-085001-7 (2011)

11. X. Li, C. Li, Y. Wang, B. Chen, T. Lim, J. of Mech. Des. - ASME, 139, 033303-1-033303-12 (2017)

12. M. Wiklo, R. Krol, K. Olejarczyk, K. Kolodziejczyk, J. of Mech. Eng. Sci. - Part C, 1 (2019)

13. Y. H. Yang, C. Chen, S. Y. Wang, Chi. J. of Mech. Eng., 1 (2018)

14. N. Kumar, V. Kosse, A. Oloyede, Mech. and Mach. The., 105, 185 (2016)

15. F. Concli, L. Maccioni, C.Gorla, Inter. Conf. On Ge. At Mun. (D), 2355, 10 (2019)

16. C. Changenet, G. Leprince, F. Ville, P. Velex, J. of Mech. Des., 133, 12, 121009-1-121009-5 (2011)

17. I. Knezevic, A. Zivkovic, M. B. Sejat, M. Rackov, M. Zeljkovic and N. F. Cofaru, MSE, Analysis the amount of lubrication and roughness of raceways on dynamic behavior on the ball bearing, (Sibiu, Romania, 2019)

18. M. Rackov, S. Kuzmanovic, I Knezevic, M. Cavic, M. Pencic, D. Cavic and N. F. Cofaru, MSE, Analysis of Possible Concept Solutions of Chain Drives, (Sibiu, Romania, 2019)

19. N. F. Cofaru, M. D. Jichişan, ATN - Series: Appl. math., mech. and engin., 42, 143 (1999)

20. A. Palmgren, Ball and Roller Bearing Engineering, SKF Industries (1959)

21. T.A. Harris, M.N. Kotzalas, Rolling Bearing Analysis - Essential Concepts of Bearing Technology, Fifth edition, Taylor \& Francis Group (2007)

22. FAG, Lubrication of Rolling Bearings (2013)

23. M. Lehmann, PhD Thesis, Technical University of Munich, Munich (1976)

24. M. Blagojevic, Master's Thesis, Faculty of Engineering University of Kragujevac, Kragujevac (2003)

25. SKF, Maintenance and Lubrication Products (2006)

26. M. Chmurawa, A. John, Inter. Conf. on Num. Anal. and Its Appl., 772 (2000) 